\title{
DEGRADAÇÃO DE RESÍDUOS ORGÂNICOS PROVENIENTES DA SUINOCULTURA EMPREGANDO O PROCESSO DE BIOAUMENTAÇÃO
}

\author{
Soraya Moreno Palácio \\ Laércio Miguel Richter ${ }^{2}$ \\ Dilcemara Cristina Zenatti ${ }^{3}$ \\ Tatiany Aparecida Barbiero Tomimitsu ${ }^{1}$ \\ Daniele Alves Nogueira ${ }^{4}$
}

\begin{abstract}
Resumo: A aplicação de resíduos orgânicos provenientes da suinocultura no solo pode suprir a demanda de nitrogênio nas plantas. Entretanto, aplicaçôes contínuas ou de altas doses, podem causar sérios danos ao ambiente e à saúde humana. Dessa forma os objetivos deste trabalho foram 1) estudar o efeito da bioaumentação na aceleração da degradação de dejetos de suínos no solo; e 2) avaliar a redução da lixiviação de formas nitrogenadas, com ênfase no nitrato. Para tanto, três experimentos foram conduzidos: 1) estudo do efeito da inoculação de bactérias do gênero Bacillus na taxa de respiração em solo adubado com dejeto de suínos; 2) efeito da inoculação na redução da carga poluidora de dejetos de suínos através da avaliação da DQO, nitrogênio orgânico e amônia; e 3) efeito da inoculação na lixiviação de formas nitrogenadas (amônia, nitrito e nitrato) em solos adubado com dejeto de suínos. O inóculo utilizado foi uma mistura de três espécies em quantidades iguais: $B$. subtilis, B. licheniformis e B. polymyxa. A produção de $\mathrm{CO}_{2}$ não aumentou em função da inoculação dos micro-organismos, porém houve uma redução da carga orgânica no segundo experimento, mostrando que a inoculação favoreceu a degradação. A diminuição da lixiviação de nitrato com o acúmulo de amônia, mostrada no terceiro experimento evidenciou a reação de desnitrificação, envolvendo a redução do nitrato a amônia via nitrito, que ocorre em conjunto com o processo de metanogênese, o que justifica a degradação sem aumento na produção de $\mathrm{CO}_{2}$.
\end{abstract}

Palavras-chave: bioaumentação, Bacillus, suinocultura, nitrato.

\begin{abstract}
The application of organic waste from swine in the soil can supply the demand for nitrogen in plants. However, continuous applications or high doses, can cause serious environmental and human health. Thus the objectives of this study were 1) to study the effect of bioaugmentation in accelerating the degradation of swine manure in the soil and 2) evaluate the reduction of nitrogen leaching forms, with emphasis on nitrate. To this end, three experiments were conducted: 1) studying the effect of inoculation with bacteria of the genus Bacillus in the rate of respiration in soil fertilized with swine manure, 2) inoculation effect in reducing the pollutant load of pig manure by evaluating the COD, organic nitrogen and ammonia, and 3) effect of inoculation on nitrogen leaching forms (ammonia, nitrite and nitrate) in soils fertilized with swine manure. The inoculum used was a mixture of three species in equal amounts, namely: B. subtilis, B. licheniformis and $\mathrm{B}$. polymyxa. $\mathrm{CO}_{2}$ production was not increased due to inoculation of the microorganism, but there was a reduction of organic load in the second experiment, showing that inoculation enhanced the degradation. The decrease in nitrate leaching with the accumulation of ammonia, shown in the third experiment shows the denitrification reaction involving the reduction of nitrate to ammonia via nitrite in a process called ammonification, which justifies the degradation without increased production of $\mathrm{CO}_{2}$.
\end{abstract}

Keywords: bioaugmentation, Bacillus, swine, nitrate.

\footnotetext{
1 Programa de Pós-Graduação em Engenharia Química da Universidade Estadual do Oeste do Paraná.

2 Departamento de Biocombustíveis da Universidade Federal do Paraná.

Biotecnal Soluções Ambientais LTDA. Toledo-PR.

4 Curso de Engenharia Química da Universidade Estadual do Oeste do Paraná.
} 


\section{INTRODUÇÃO}

A suinocultura é uma atividade econômica bastante difundida no sul do Brasil e um dos maiores entraves para a expansão nas pequenas e médias propriedades, tem sido o excesso de produção de dejetos. Estes dejetos, quando mal manejados, causam danos ao ambiente e à saúde humana.

Inúmeras técnicas de tratamento dos dejetos podem ser utilizadas, como o uso de lagoas, reator anaeróbio de fluxo ascendente com manta de lodo (Reator UASB), esterqueira e bioesterqueira (formas de armazenamento que proporcionam redução da fração orgânica associada à sua liquefação, preservando o potencial de fertilização desse produto) (Belli Filho et al. 2001) ou biodigestão anaeróbica (Souza et al. 2005), antes do seu uso como fertilizante.

O manejo inadequado dos resíduos da suinocultura (extravasamento de esterqueiras, aplicação excessiva no solo, para citar alguns) pode ocasionar a contaminação de rios, levando à eutrofização; de lençóis subterrâneos, ocasionando o aumento da concentração do íon nitrato; do solo, inserindo patógenos e excesso de nutrientes, dentre outros; e do ar, com emissóes gasosas (Kunz et al. 2005).

Uma das técnicas atualmente disponíveis é a biorremediação que se baseia na capacidade de alguns organismos (micro-organismos e/ou plantas) crescerem na presença de contaminantes, removendo estas substâncias devido à ação de seu metabolismo ou mesmo acumulando tais compostos (Vidalli 2001).

O uso de micro-organismos na biorremediação pode ocorrer por espécies autóctones, alóctones ou combinação de ambos, que através do metabolismo correspondente podem formar compostos menos tóxicos ou promoverem total mineralização do contaminante produzindo dióxido de carbono e água (Boopathy 2000).

De acordo com Ollivier \& Magot (2005) existem alguns métodos aplicados à biorremediação para acelerar a biodegradação. Estes métodos podem ser divididos em bioestimulação e bioaumentação. A bioestimulação é definida como a melhoria dos fatores ambientais e, dentre eles, destacam-se o $\mathrm{pH}$, o teor de umidade, a temperatura, a correção de nutrientes (fontes de carbono orgânico, fósforo, nitrogênio, etc.) e de aceptores finais de elétrons. A bioaumentação, por sua vez, baseia-se na aceleração e aumento da eficiência de degradação do poluente pela inserção de linhagens alóctones que vão agir concomitantemente com os micro-organismos autóctones.

Segundo Bento et al. (2005), a melhor performance da bioaumentação pode ser atingida pelo emprego dos micro-organismos previamente selecionados aumentando assim a população e diversidade microbiana. A partir desse pressuposto, o aumento da comunidade microbiana específica, em conjunto com a adição de nutrientes, promove uma redução substancial no tempo de tratamento.

A bioaumentação pode ser uma alternativa para aumentar a degradação de resíduos no solo e diminuir as perdas por lixiviação.

Dessa forma o objetivo deste trabalho foi estudar o efeito da bioaumentação na degradação de dejetos de suínos no solo, empregando-se bactérias do gênero Bacillus. Para tanto, três experimentos foram conduzidos: 1) estudo do efeito da inoculação na taxa de respiração em solo adubado com dejeto de suínos; 2) efeito da inoculação na redução da carga poluidora de dejetos de suínos e 3) efeito da inoculação na lixiviação de formas nitrogenadas em solos tratados com dejeto de suínos.

\section{MATERIAIS E MÉTODOS}

O inóculo utilizado nos experimentos é uma mistura de bactérias do gênero Bacillus compreendendo três espécies em quantidades iguais, a saber: $B$. subtilis, B. licheniformis e B. polymyxa totalizando $1,7 \times 10^{8}$ UFC (unidade formadora de colônia) por grama de inóculo. O solo (Latossolo Vermelho Eutroférrico) foi coletado na camada de $0-20 \mathrm{~cm}$, seco em temperatura ambiente, peneirado em malha de $2 \mathrm{~mm}$ e caracterizado quimicamente. $\mathrm{O}$ dejeto de suínos foi obtido em granja localizada na região oeste do Paraná, sendo caracterizado e utilizado in natura. Os demais reagentes utilizados foram de grau analítico.

\subsection{TAXA DE RESPIRAÇÃO DO SOLO}

Para avaliar o efeito da inoculação de bactérias do gênero Bacillus na taxa de respiração em solo adubado com dejeto de suínos, foram medidas as quantidades de $\mathrm{CO}_{2}$ emitidos durante a degradação, pelo teste da respirometria de Bartha (ABNT, 1999). 
Na montagem do respirômetro foram utilizados $130 \mathrm{~g}$ de solo (Latossolo Vermelho Eutroférrico) coletado na camada de $0-20 \mathrm{~cm}$, seco e peneirado em malha de $2 \mathrm{~mm}$, onde foram incorporados o dejeto de suíno in natura recém coletado, na dosagem de $\mathrm{A}=$ sem dejeto, $\mathrm{B}=23$ e $\mathrm{C}=46$ ton ha ${ }^{-1}$. Para cada dose de dejeto aplicada, foram inoculadas 3 doses de inóculo contendo bactérias do gênero $B a-$ cillus, sendo $\mathrm{D}_{0}=$ sem inóculo; $\mathrm{D}_{1}=5,28 \times 10^{7}, \mathrm{D}_{2}$ $=10,6 \times 10^{7}$ e $\mathrm{D}_{3}=15,9 \times 10^{7} \mathrm{UFC} \mathrm{Kg}^{-1}$ de dejeto, em triplicata. $\mathrm{O}$ conteúdo dos respirômetros foram homogeneizados e umidecidos com água suficiente para atingir $60 \%$ da capacidade de saturação do solo. $\mathrm{O}$ solo e o dejeto não foram esterilizados.

No interior de cada respirômetro foi colocado um copo plástico contendo $20,0 \mathrm{~mL}$ de $\mathrm{NaOH} 0,5 \mathrm{~mol} \mathrm{~L}^{-1}$ para captura do $\mathrm{CO}_{2}$. Trocou-se o $\mathrm{NaOH}$ diariamente até o 90 dia, a cada dois dias até $21^{\circ}$ e depois semanalmente totalizando 76 dias. Ao $\mathrm{NaOH}$ retirado do respirômetro adicionou-se $1,0 \mathrm{~mL}$ de $\mathrm{BaCl}_{2}$ saturado e o excesso de $\mathrm{NaOH}$ foi titulado com $\mathrm{HCl} 0,5 \mathrm{~mol} \mathrm{~L}^{-1}$. Calculou-se a quantidade de $\mathrm{CO}_{2}$ acumulado em $\mathrm{mg} \mathrm{Kg}{ }^{-1}$ de solo.

\subsection{REDUÇÃO DA CARGA POLUIDORA}

Para avaliar o efeito da inoculação de bactérias do gênero Bacillus na redução da carga poluidora de dejetos de suínos, conduziu-se um experimento utilizando-se um delineamento inteiramente casualizado (DIC) balanceado, com um fator (dose de inóculo). Pesou-se $500 \mathrm{~g}$ de dejeto e aplicou-se 3 doses do Bacillus, sendo: $\mathrm{D}_{0}=$ sem inóculo; $\mathrm{D}_{1}=5,28 \times 10^{7} ; \mathrm{D}_{2}=10,6 \times 10^{7} \mathrm{e}$ $\mathrm{D}_{3}=15,9 \times 10^{7} \mathrm{UFC} \mathrm{Kg}{ }^{-1}$ de dejeto, em triplicata. Os tratamentos foram mantidos com a umidade natural do dejeto com adição periódica de água deionizada, mantendo-se o peso constante. Após 28 dias determinou-se os valores de DQO, nitrogênio orgânico total e amônia, conforme metodologia descrita em APHA (1998). As médias obtidas foram comparadas pelo teste de Tukey à nível de $5 \%$ de significância.

\subsection{LIXIVIAÇÃO DAS FORMAS NITROGENADAS}

Para estudar o efeito da inoculação de bactérias do gênero Bacillus na lixiviação de formas nitrogenadas em solos tratados com dejeto de suínos, conduziu-se um experimento utilizando colunas de percolação de $25 \mathrm{~cm}$ de altura e $10 \mathrm{~cm}$ de diâmetro, que apresentavam na base uma abertura protegida por uma tela fina de plástico conectada a uma mangueira flexível de $0,5 \mathrm{~cm}$ de diâmetro que permitia a condução do líquido percolado através do solo para recipiente coletor. $\mathrm{O}$ experimento foi conduzido utilizando-se o delineamento inteiramente casualizado num esquema de arranjo fatorial 4 x 4 (4 doses de inóculo: $\mathrm{D}_{0}, \mathrm{D}_{1}, \mathrm{D}_{2}$ e $\mathrm{D}_{3}$ e quatro tempos de incubação: 5, 29, 64 e 89 dias).

Nas colunas foram colocados solo seco em quantidade suficiente para obter uma altura de 20 cm (1900 g). Adicionou-se 23 ton ha ${ }^{-1}$ de dejeto (base úmida) e o inóculo nas doses $\mathrm{D}_{0}=$ sem inóculo; $\mathrm{D}_{1}=5,28 \times 10^{7}, \mathrm{D}_{2}=10,6 \times 10^{7}$ e $\mathrm{D}_{3}=$ $15,9 \times 10^{7} \mathrm{UFC} \mathrm{Kg^{-1 }}$ de dejeto, com 12 réplicas. Manteve-se a umidade adicionando água deionizada em quantidade para proporcionar condiçôes de umidade para a degradação da carga orgânica do dejeto pela microbiota presente sem contudo permitir lixiviação.

As colunas foram lixiviadas com $1500 \mathrm{~mL}$ de água deionizada, 3 réplicas aos 5 dias de incubação, 3 aos 29, 3 aos 64 e 3 aos 89 dias de incubação, sendo em seguida descartadas. A quantidade de água correspondeu a quatro vezes a capacidade de retenção do solo.

Para promover a lixiviação, o solo foi saturado lentamente e posteriormente permitiu-se a passagem de mais líquido, através de um sistema de

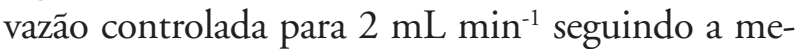
todologia empregada por Bertoncini \& Mattiazzo (1999). No líquido percolado foram determinados os valores de amônia, nitrato e nitrito, segundo metodologia descrita em APHA (1998). A análise estatística foi realizada por meio de equaçōes de regressão não-linear e identidade de modelos, através do teste da razão de verossimilhança, descrita por Regazzi (2003), com o propósito de avaliar a possibilidade de uma única equação representar o comportamento das variáveis estudadas. Para cada variável, foram testadas todas as combinações que representam as várias possibilidades de agrupamento entre as quatro doses estudadas.

\section{RESULTADOS E DISCUSSÃO}

O solo utilizado nos experimentos apresentou as seguintes características: 0,14 e 0,32 $\mathrm{g} \mathrm{dm}^{-3}$ de fósforo e matéria orgânica, respectivamente; 
1,$88 ; 10,00$ e 4,30 $\mathrm{cmol}_{c} \mathrm{dm}^{-3} \mathrm{de} \mathrm{H}^{+}+\mathrm{Al}^{3+}, \mathrm{Ca}^{2+} \mathrm{e}$ $\mathrm{Mg}^{2+}$, respectivamente e o $\mathrm{pH}$ foi de 5,27.

$\mathrm{O}$ dejeto de suíno apresentou 11,040 \pm $134 ; 7,766 \pm 105 ; 578 \pm 47 ; 536 \pm 38 \mathrm{mg} \mathrm{L}^{-1}$ de DQO, nitrogênio orgânico, fósforo e potássio, respectivamente.

\subsection{TAXA DE RESPIRAÇÃO DO SOLO}

A taxa de respiração do solo foi avaliada pela geração efetiva acumulada (GEA) de $\mathrm{CO}_{2}$, como mostra a Figura 1. O aumento da GEA foi proporcional à dose de dejeto aplicada, sem dejeto a concentração de $\mathrm{CO}_{2}$ acumulado foi de aproximadamente $200 \mathrm{mg} \mathrm{Kg}^{-1}$, enquanto que para as doses $\mathrm{B}$ e C, foram de 400 e $600 \mathrm{mg} \mathrm{Kg}^{-1}$. A produção de $\mathrm{CO}_{2}$ no tratamento sem aplicação de dejeto foi devido à degradação da matéria orgânica presente no solo.

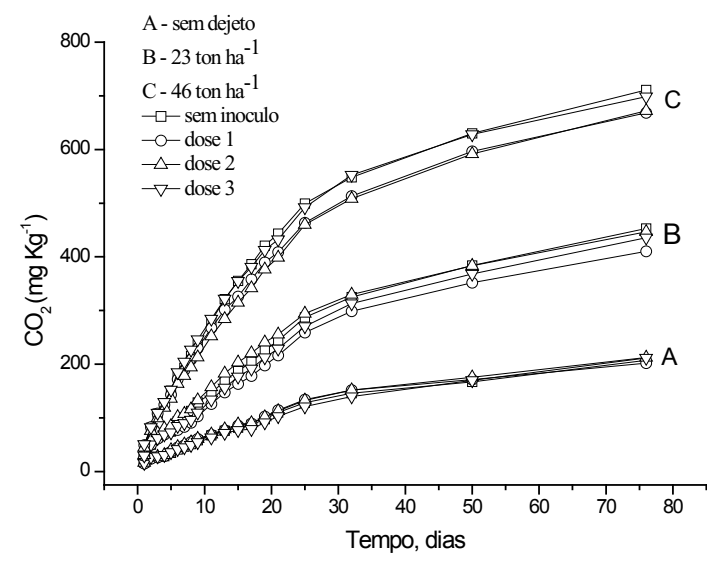

Figura 1. Geração efetiva de $\mathrm{CO}_{2}$ acumulado para aplicação de dejeto de suíno nas doses: $\mathrm{A}$ = sem dejeto; $\mathrm{B}=23$ e C $=46$ ton ha ${ }^{-1}$, com aplicação de 4 doses de dejeto: $\mathrm{D}_{0}=$ sem inóculo; $\mathrm{D}_{1}=5,28 \times 10^{7}, \mathrm{D}_{2}=10,6 \times 10^{7}$ e $\mathrm{D}_{3}=15,9 \times$

$10^{7} \mathrm{UFC} \mathrm{Kg}^{-1}$ de dejeto em triplicata.

A inoculação das bactérias do gênero $B a$ cillus não aumentou a produção de $\mathrm{CO}_{2}$. As amostras sem dejeto, contendo as doses $\mathrm{D}_{1}, \mathrm{D}_{2}$ e $\mathrm{D}_{3}$ do inóculo foram equivalente à $\mathrm{D}_{0}$ (sem inóculo), o mesmo ocorreu para as amostras com dejeto. Os micro-organismos presentes no solo e no dejeto desempenharam papel fundamental na degradação da matéria orgânica.

Nesse estudo não foi analisado o teor de carbono orgânico após o período de incubação. Embora não tenha sido medido, com a degradação da matéria orgânica pode ter havido a formação de metano $\left(\mathrm{CH}_{4}\right)$ e água, além do $\mathrm{CO}_{2}$.
Segundo Alves et al. (2004), há evidências de que a digestão anaeróbia com formação de metano seja responsável pela completa mineralização de 5 a $10 \%$ de toda a matéria orgânica disponível na Terra. O processo de formação do gás metano se refere às reações de fermentação da matéria orgânica, pelo qual a matéria orgânica se auto-oxida através do rearranjo de elétrons na molécula fermentada.

De acordo com Lubberding (1995), a metanogênese pode ocorrer por dois caminhos. O primeiro denomina-se metanogênese hidrogenotrófica (produção de metano a partir de hidrogênio), realizado por praticamente todas as bactérias metanogênicas (reação 1). O segundo e principal caminho, denominado metanogênese acetotrófica e representado pela reação 2, é realizado por poucas espécies de bactérias, porém é responsável pela maior parte das conversóes, convertendo o carbono orgânico na forma de acetato a metano.

$$
\begin{aligned}
& \mathrm{CO}_{2}+4 \mathrm{H}_{2} \rightarrow 2 \mathrm{H}_{2} \mathrm{O}+\mathrm{CH}_{4} \\
& \mathrm{CH}_{3} \mathrm{COOH} \rightarrow \mathrm{CO}_{2}+\mathrm{CH}_{4}
\end{aligned}
$$

Neste experimento, o metano também não foi quantificado, mas foi observado a formação de maior volume de água nos tratamentos com a presença do inóculo.

\subsection{REDUÇÃO DA CARGA POLUIDORA}

O percentual de redução de nitrogênio orgânico, amônia e DQO em dejetos de suínos, tratados com doses crescentes de bactérias do gênero Bacillus, após 28 dias de incubação são mostrados na Figura 2. Os valores de $\mathrm{pH}$ sofreram redução de 8,1 para 7,5 em todos os tratamentos.

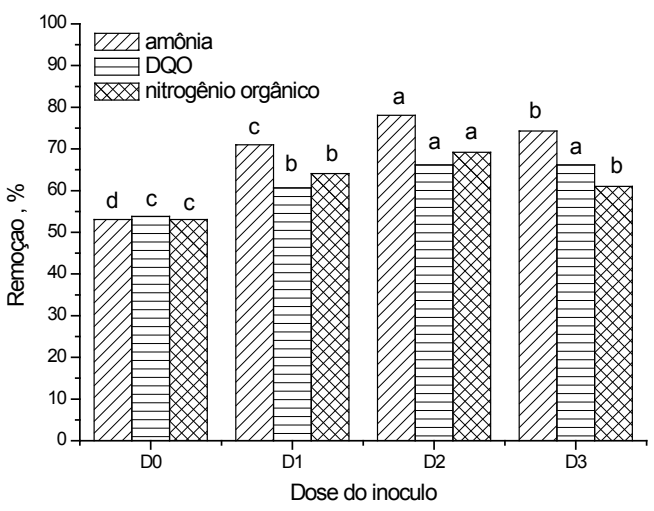

Figura 2. Remoção percentual de nitrogênio orgânico, amônia e DQO em dejeto de suínos após a aplicação de bactérias do gênero Bacillus 
nas doses: $\mathrm{D}_{0}=$ sem inóculo; $\mathrm{D}_{1}=5,28 \times 10^{7}$; $\mathrm{D}_{2}=10,6 \times 10^{7} \mathrm{e} \mathrm{D}_{3}=15,9 \times 10^{7} \mathrm{UFC} \mathrm{Kg}^{-1} \mathrm{de}$ dejeto. As médias seguidas pelas mesmas letras, não diferem estatisticamente entre si, pelo teste de Tukey, a 5\%.

Após 28 dias de incubação houve uma redução dos valores de nitrogênio orgânico, amônia e DQO, em todos os tratamentos, no qual o percentual de redução foi maior nos tratamentos onde houve aplicação do inóculo, mostrando que as bactérias inoculadas atuaram na degradação do resíduo.

Nos tratamentos onde houve inoculação das bactérias do gênero Bacillus, o nitrogênio orgânico apresentou uma redução significativamente maior em relação às amostras não inoculadas. Os valores de redução foram 69, 64, 61 e $53 \%$, para $\mathrm{D}_{2}, \mathrm{D}_{1}, \mathrm{D}_{3}$ e $\mathrm{D}_{0}$, respectivamente.

A remoção da amônia foi maior com a dose $\mathrm{D}_{2}(78 \%)$. Para as doses $\mathrm{D}_{3}$ e $\mathrm{D}_{1}$ os percentuais de remoção foram 74 e $71 \%$, respectivamente e $53 \%$ quando não houve inoculação de bactérias. Para a remoção da DQO as doses 2 e 3 foram equivalentes $(66 \%)$, apresentando valores maiores que as doses $\mathrm{D}_{1}(61 \%)$ e $\mathrm{D}_{0}(54 \%)$.

As bactérias endógenas do dejeto foram responsáveis pela redução de aproximadamente 55\% do nitrogênio orgânico, amônia e DQO e as bactérias inoculadas incrementaram uma redução em torno de $20 \%$ desses parâmetros, evidenciando o potencial biotecnológico dessas bactérias para o tratamento desse resíduo. $\mathrm{O}$ tratamento pode ser otimizado controlando-se as variáveis: dose de inóculo, $\mathrm{pH}$, temperatura e equilíbrio nutricional que são parâmetros operacionais fundamentais para a melhoria do processo.

\subsection{LIXIVIAÇÃO DAS FORMAS NITROGENADAS}

A mineralização do nitrogênio orgânico inicia-se com a sua oxidação biológica em $\mathrm{NH}_{4}^{+}$ e na sequência, o processo biológico de remoção de nitrogênio, ocorre em duas fases distintas, a nitrificação, onde $\mathrm{o}_{4}^{+}$é convertido a $\mathrm{NO}_{3}^{-}$e a desnitrificação, onde $\mathrm{o} \mathrm{NO}_{3}^{-}$produzido é reduzido a $\mathrm{N}_{2}$.

A nitrificação é um processo aeróbio e autotrófico. Espécies pertencentes ao gênero Nitrosomonas (que oxidam $\mathrm{NH}_{4}^{+}$a $\mathrm{NO}_{2}^{-}$) e Nitrobacter (que oxidam $\mathrm{NO}_{2}^{-}$a $\mathrm{NO}_{3}^{-}$) são responsáveis pela maior parte da nitrificação na natureza (Anthonisen et al. 1976). Como as bactérias nitrificantes são autotróficas, seu crescimento não depende da matéria orgânica, utilizando o $\mathrm{CO}_{2}$ como fonte de carbono. Metcalf \& Eddy (2003) apresentam um valor teórico de $7,14 \mathrm{~g}$ de alcalinidade $\left(\mathrm{CaCO}_{3}\right)$ para converter um grama de amônia em nitrato. $\mathrm{O} \mathrm{O}_{2}$ atua como aceptor de elétron na oxidação do íon amônio a nitrito e este posteriormente a nitrato segundo as reações 3 e 5 .

$$
\begin{aligned}
& \mathrm{NH}_{4}^{+}+1,5 \mathrm{O}_{2} \rightarrow \mathrm{NO}_{2}^{-}+2 \mathrm{H}^{+}+\mathrm{H}_{2} \mathrm{O} \\
& \mathrm{NO}_{2}{ }^{-}+0,5 \mathrm{O}_{2} \rightarrow \mathrm{NO}_{3}^{-}
\end{aligned}
$$

Utilizando-se os valores médios obtidos nesse estudo, para a lixiviação de amônia, nitrito e nitrato, construiu-se as curvas de concentração em função do tempo de incubação para cada dose de inóculo aplicada (Fig. 3, 4 e 5) e ajustou-se os modelos de regressão não linear apresentadas na Tab. 1 .

\begin{tabular}{|c|c|c|c|c|c|c|c|}
\hline Tratamento & Modelo & $\mathrm{a}$ & $\mathrm{b}$ & c & $\mathrm{d}$ & $\mathrm{R}^{2}$ ajustado & Prob $>F^{*}$ \\
\hline \multicolumn{8}{|c|}{ Amônia } \\
\hline $\mathrm{D}_{0}$ & $\operatorname{Mod}_{1}$ & 0,34 & $-0,01$ & $1,0 \times 10^{-4}$ & - & 0,99 & $S$ \\
\hline $\mathrm{D}_{1}$ & $\operatorname{Mod}_{2}$ & $-0,62$ & 0,18 & $-5,0 \times 10^{-3}$ & $2,8 \times 10^{-5}$ & 0,99 & $S$ \\
\hline $\mathrm{D}_{2}$ & $\operatorname{Mod}_{2}$ & $-0,57$ & 0,13 & $-3,0 \times 10^{-3}$ & $1,9 \times 10^{-5}$ & 0,98 & $S$ \\
\hline $\mathrm{D}_{3}$ & $\operatorname{Mod}_{2}$ & 0,29 & 0,04 & $-1,0 \times 10^{-3}$ & $9,0 \times 10^{-6}$ & 0,99 & $S$ \\
\hline
\end{tabular}

Tabela 1. Valores encontrados para os parâmetros dos modelos. 


\begin{tabular}{|c|c|c|c|c|c|c|c|}
\hline \multicolumn{7}{|c|}{ Nitrito } \\
\hline $\mathrm{D}_{0}$ & $\operatorname{Mod}_{2}$ & 0,40 & $-0,03$ & $6,1 \times 10^{-4}$ & $-3,4 \times 10^{-6}$ & 0,98 & $\mathrm{~S}$ \\
\hline $\mathrm{D}_{1}$ & $\operatorname{Mod}_{2}$ & 0,28 & $-0,03$ & $1,0 \times 10^{-3}$ & $-7,5 \times 10^{-6}$ & 0,99 & $\mathrm{~S}$ \\
\hline $\mathrm{D}_{2}$ & $\operatorname{Mod}_{2}$ & 0,15 & $-0,01$ & $3,9 \times 10^{-4}$ & $-2,5 \times 10^{-6}$ & 0,98 & $\mathrm{~S}$ \\
\hline $\mathrm{D}_{3}$ & $\operatorname{Mod}_{2}$ & 0,21 & $-0,01$ & $3,0 \times 10^{-4}$ & $-1,9 \times 10^{-6}$ & 0,97 & $\mathrm{~S}$ \\
\hline \multicolumn{7}{|c|}{ Nitrato } \\
\hline $\mathrm{D}_{0}$ & $\operatorname{Mod}_{2}$ & 7,83 & 0,28 & $-2,0 \times 10^{-3}$ & $1,7 \times 10^{-6}$ & 0,98 & $\mathrm{~S}$ \\
\hline $\mathrm{D}_{1}$ & $\operatorname{Mod}_{2}$ & 3,04 & 0,97 & $-2,5 \times 10^{-2}$ & $1,7 \times 10^{-4}$ & 0,99 & $\mathrm{~S}$ \\
\hline $\mathrm{D}_{2}$ & $\operatorname{Mod}_{2}$ & 12,32 & $-0,84$ & $2,6 \times 10^{-2}$ & $-1,9 \times 10^{-4}$ & 0,99 & $\mathrm{~S}$ \\
\hline $\mathrm{D}_{3}$ & $\operatorname{Mod}_{2}$ & 16,01 & $-0,84$ & $1,7 \times 10^{-2}$ & $-1,0 \times 10^{-4}$ & 0,98 & $\mathrm{~S}$ \\
\hline
\end{tabular}

*Prob $>$ F denota a significância estatística dos modelos à nível de $5 \%$ de probabilidade, obtida através de Análise de Variância, sendo: Mod $:$ Y $=a+b x+c x^{2} ; \operatorname{Mod}_{2}: Y=a+b x+c x^{2}+d x^{3} ; S=$ significativo e $N=$ não significativo.

Os modelos ajustados foram polinômios de ordem 3, exceto na curva de amônia para a dose $\mathrm{D}_{0}$ onde houve melhor ajuste para um polinômio de ordem 2. Os valores de $\mathrm{R}_{\text {ajustado }}^{2}$ foram próximos de 100 \%. Segundo Regazzi (2003), os valores de $\mathrm{R}_{\text {ajustado }}^{2}$ encontrados na literatura são, em sua maioria, próximos a $100 \%$, mesmo havendo enorme variação entre os valores observados e preditos. $\mathrm{O} \mathrm{R}^{2}$ não tem qualquer significado óbvio para modelos de regressão não-linear como único critério de seleção (Ratkowsky 1990). O parâmetro Prob $>\mathrm{F}^{*}$ obtido do teste de Análise de Variância (ANOVA) valida os modelos, seus valores foram menores que 0,05 para todos os modelos mostrando suas significâncias à nível de $5 \%$ de probabilidade.

$\mathrm{Na}$ Tab. 2, são apresentados os resultados dos testes de identidade entre modelos ao nível de $5 \%$ de probabilidade. Para a variável dose de inóculo, obtiveram-se os seguintes resultados: os testes de identidade foram significativos para todas as combinações, mostrando que não há possibilidade de agrupamento, isto é, existem variações no formato das curvas para as diferentes doses de inóculo estudadas e deve ser utilizada uma equação distinta para cada uma delas.

Tabela 2. Resultado do teste de identidade para as variáveis estudadas em todas as combinaçôes entre modelos $\mathrm{D}_{0}, \mathrm{D}_{1}, \mathrm{D}_{2}$ e $\mathrm{D}_{3}$.

\begin{tabular}{|c|c|c|c|}
\hline Combinaçáo & GL & $\mathbf{c}^{2}$ calculado & $\begin{array}{c}\text { Valor-P } \\
\mathbf{P}\left(\boldsymbol{\chi}_{\mathbf{t}}^{\mathbf{}}>\boldsymbol{\chi}^{\mathbf{2}} \text { calculado }\right)\end{array}$ \\
\hline \multicolumn{4}{|c|}{ Amônia } \\
\hline $\mathrm{D}_{0} \mathrm{D}_{1} \mathrm{D}_{2} \mathrm{D}_{3}$ & 1 & 36,11 & $\mathrm{P}<0,01$ \\
\hline $\mathrm{D}_{0} \mathrm{D}_{1} \mathrm{D}_{2}$ & 1 & 35,61 & $\mathrm{P}<0,01$ \\
\hline $\mathrm{D}_{0} \mathrm{D}_{2} \mathrm{D}_{3}$ & 1 & 34,87 & $\mathrm{P}<0,01$ \\
\hline $\mathrm{D}_{1} \mathrm{D}_{2} \mathrm{D}_{3}$ & 1 & 35,28 & $\mathrm{P}<0,01$ \\
\hline $\mathrm{D}_{0} \mathrm{D}_{1}$ & 1 & 2,07 & $\mathrm{P}<0,01$ \\
\hline $\mathrm{D}_{0} \mathrm{D}_{2}$ & 1 & 34,38 & $\mathrm{P}<0,01$ \\
\hline $\mathrm{D}_{0} \mathrm{D}_{3}$ & 1 & 1,33 & $\mathrm{P}<0,01$ \\
\hline $\mathrm{D}_{1} \mathrm{D}_{2}$ & 1 & 34,78 & $\mathrm{P}<0,01$ \\
\hline $\mathrm{D}_{1} \mathrm{D}_{3}$ & 1 & 1,73 & $\mathrm{P}<0,01$ \\
\hline $\mathrm{D}_{2} \mathrm{D}_{3}$ & 1 & 34,04 & $\mathrm{P}<0,01$ \\
\hline
\end{tabular}




\begin{tabular}{|c|l|l|l|}
\hline \multicolumn{4}{|c|}{ Nitrito } \\
\hline $\mathrm{D}_{0} \mathrm{D}_{1} \mathrm{D}_{2} \mathrm{D}_{3}$ & 1 & 7,23 & $\mathrm{P}<0,01$ \\
\hline $\mathrm{D}_{0} \mathrm{D}_{1} \mathrm{D}_{2}$ & 1 & 5,56 & $\mathrm{P}<0,01$ \\
\hline $\mathrm{D}_{0} \mathrm{D}_{2} \mathrm{D}_{3}$ & 1 & 5,38 & $\mathrm{P}<0,01$ \\
\hline $\mathrm{D}_{1} \mathrm{D}_{2} \mathrm{D}_{3}$ & 1 & 6,33 & $\mathrm{P}<0,01$ \\
\hline $\mathrm{D}_{0} \mathrm{D}_{1}$ & 1 & 2,76 & $\mathrm{P}<0,01$ \\
\hline $\mathrm{D}_{0} \mathrm{D}_{2}$ & 1 & 3,70 & $\mathrm{P}<0,01$ \\
\hline $\mathrm{D}_{0} \mathrm{D}_{3}$ & 1 & 2,58 & $\mathrm{P}<0,01$ \\
\hline $\mathrm{D}_{1} \mathrm{D}_{2}$ & 1 & 4,66 & $\mathrm{P}<0,01$ \\
\hline $\mathrm{D}_{1} \mathrm{D}_{3}$ & 1 & 3,53 & $\mathrm{P}<0,01$ \\
\hline $\mathrm{D}_{2} \mathrm{D}_{3}$ & 1 & 4,48 & $\mathrm{P}<0,01$ \\
\hline & & & \\
\hline $\mathrm{D}_{0} \mathrm{D}_{1} \mathrm{D}_{2} \mathrm{D}_{3}$ & 1 & 0,77 & $\mathrm{P}<0,01$ \\
\hline $\mathrm{D}_{0} \mathrm{D}_{1} \mathrm{D}_{2}$ & 1 & 0,75 & $\mathrm{P}<0,01$ \\
\hline $\mathrm{D}_{0} \mathrm{D}_{2} \mathrm{D}_{3}$ & 1 & 0,08 & $\mathrm{P}<0,01$ \\
\hline $\mathrm{D}_{1} \mathrm{D}_{2} \mathrm{D}_{3}$ & 1 & 0,74 & $\mathrm{P}<0,01$ \\
\hline $\mathrm{D}_{0} \mathrm{D}_{1}$ & 1 & 0,71 & $\mathrm{P}<0,01$ \\
\hline $\mathrm{D}_{0} \mathrm{D}_{2}$ & 1 & 0,06 & $\mathrm{P}<0,01$ \\
\hline $\mathrm{D}_{0} \mathrm{D}_{3}$ & 1 & 0,04 & $\mathrm{P}<0,01$ \\
\hline $\mathrm{D}_{1} \mathrm{D}_{2}$ & 1 & 0,72 & $\mathrm{P}<0,01$ \\
\hline $\mathrm{D}_{1} \mathrm{D}_{3}$ & 1 & 0,71 & $\mathrm{P}<0,01$ \\
\hline $\mathrm{D}_{2} \mathrm{D}_{3}$ & 1 & 0,05 & $\mathrm{P}<0,01$ \\
\hline
\end{tabular}

2 : valor tabelado

A lixiviação de amônia (Fig. 3) para os tratamentos onde houve inoculação das bactérias, foi maior aos 29 dias de incubação, decrescendo após este período. Com a dose $\mathrm{D}_{3}$ do inóculo houve menor liberação de $\mathrm{N}$-amoniacal do que com a dose $\mathrm{D}_{1}$ e $\mathrm{D}_{2}$, exceto para o tempo de 5 dias de incubação.

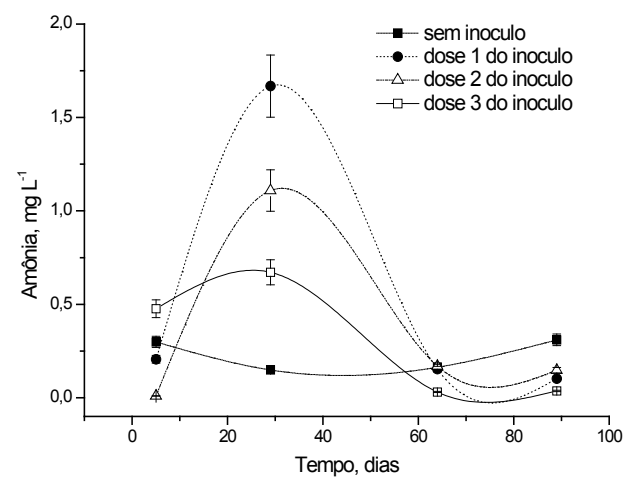

Figura 3. Concentraçôes de amônia lixiviadas $\left(\mathrm{mg} \mathrm{L}^{-1}\right)$ após o período de incubação quando foram aplicadas bactérias do gênero Bacillus nas doses: $\mathrm{D}_{0}=$ sem inóculo; $\mathrm{D}_{1}=5,28 \times 10^{7} ; \mathrm{D}_{2}=$ $10,6 \times 10^{7}$ e $\mathrm{D}_{3}=15,9 \times 10^{7} \mathrm{UFC} \mathrm{Kg}^{-1}$ de dejeto.
Na Fig. 4 observou-se uma pequena imobilização do nitrito já no $5^{\circ}$ dia de incubação, evidenciada pela menor concentração desse elemento no lixiviado. A lixiviação de nitrito no $29^{\circ}$ dia foi pequena e independente da dose de inóculo aplicada. A dose $\mathrm{D}_{3}$ produziu aos 64 e 89 dias uma menor concentração de nitrito no lixiviado.

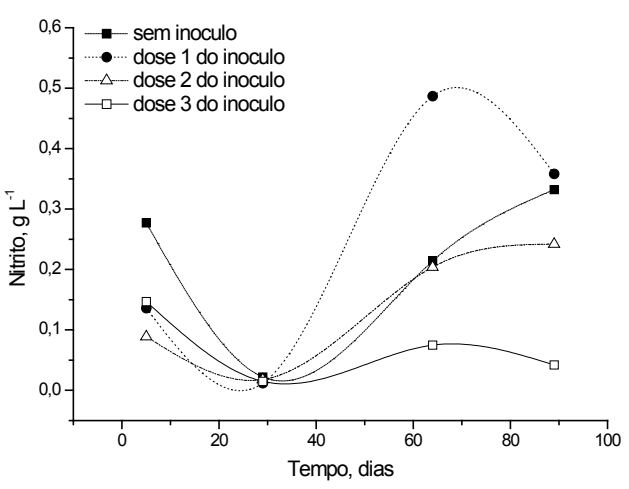

Figura 4. Concentrações de nitrito lixiviadas ( $\left.\mathrm{mg} \mathrm{L}^{-1}\right)$ após o período de incubação quando foram aplicadas bactérias do gênero Bacillus nas doses: $\mathrm{D}_{0}=$ sem inóculo; $\mathrm{D}_{1}=5,28 \times 10^{7} ; \mathrm{D}_{2}=$ $10,6 \times 10^{7} \mathrm{e} \mathrm{D}_{3}=15,9 \times 10^{7} \mathrm{UFC} \mathrm{Kg}^{-1}$ de dejeto. 
Os resultados (Fig. 5) indicaram que a dose $\mathrm{D}_{3}$ proporcionou uma menor lixiviação do nitrato ao longo do tempo, o que pode ser benéfico do ponto de vista ambiental. Essa menor lixiviação pode estar associada aos processos de imobilização bacteriana ou ainda por desnitrificação provocado por redução biológica.

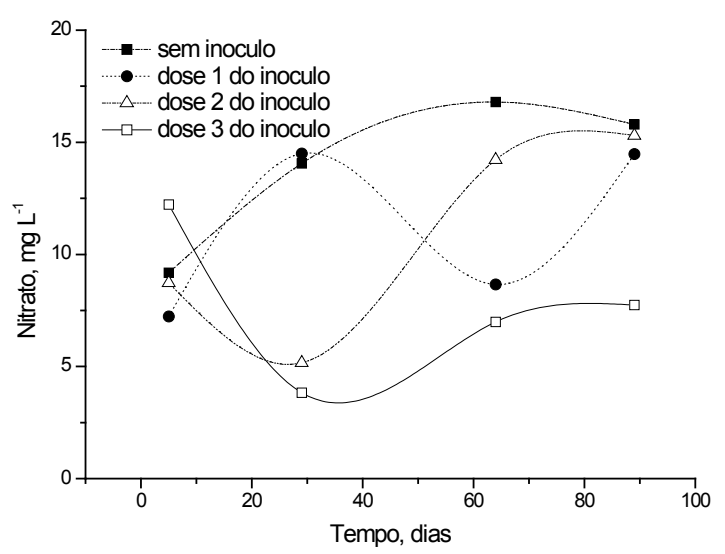

Figura 5. Concentrações de nitrato lixiviadas $\left(\mathrm{mg} \mathrm{L}^{-1}\right)$ após o período de incubação quando foram aplicadas bactérias do gênero Bacillus nas doses: $\mathrm{D}_{0}=$ sem inóculo; $\mathrm{D}_{1}=5,28 \times 10^{7} ; \mathrm{D}_{2}=$ $10,6 \times 10^{7}$ e $\mathrm{D}_{3}=15,9 \times 10^{7} \mathrm{UFC} \mathrm{Kg}^{-1}$ de dejeto.

A desnitrificação é um processo que ocorre em meio anóxico, sendo realizada por bactérias heterotróficas de vários gêneros (Pseudomonas, Bacillus, Spirillum, Hyphomicrobium, Agrobacterium, Acinetobacter, dentre outras) (Bitton 2005). $\mathrm{Na}$ etapa heterotrófica, a desnitrificação anóxica é responsável pela conversão de $\mathrm{NO}_{3}{ }^{-}$ou $\mathrm{NO}_{2}{ }^{-}$a $\mathrm{N}_{2}$ na presença de fonte de matéria orgânica, como pode ser observado nas reaçóes 5 e 6 .

$$
\begin{aligned}
& 2 \mathrm{NO}_{3}^{-}+10 \mathrm{H}^{+}+10 \mathrm{e}^{-} \rightarrow \mathrm{N}_{2}+2 \mathrm{OH}^{-}+4 \mathrm{H}_{2} \mathrm{O} \\
& 2 \mathrm{NO}_{2}^{-}+6 \mathrm{H}^{+}+6 \mathrm{e}^{-} \rightarrow \mathrm{N}_{2}+2 \mathrm{OH}^{-}+2 \mathrm{H}_{2} \mathrm{O}
\end{aligned}
$$

Essa redução biológica de nitrato pode ser assimilatória ou dissimilatória. Quando é assimilatória envolve a redução do nitrato a nitrito e então a amônia, que é utilizada para a síntese celular. Esta redução é regulada pela quantidade de amônia no meio e é comum nos casos onde o nitrato é a única fonte de nitrogênio. Plantas, fungos, algas e algumas bactérias facultativas são capazes de realizar esse processo (Akunna et al. 1992; Drtil 1995).

A desnitrificação, propriamente dita, é a redução do nitrato em condições anóxicas onde bactérias utilizam nitrato, em vez de oxigênio, como aceptor final de elétrons, sendo chamada redução biológica dissimilatória. Dois tipos de reação caracterizam este processo: na primeira reação, o nitrato é reduzido a nitrito, o qual é, depois, reduzido a produtos gasosos tais como nitrogênio molecular ou óxido nitroso, em um processo também chamado respiração do nitrato. As reaçôes 5 , 6 e 7 caracterizam o processo de desnitrificação (Metcalf \& Eddy 1991; Akunna et al. 1992; Drtil 1995; Bernet \& Moletta 1998):

$$
\mathrm{NO}_{3}{ }^{-} \rightarrow \mathrm{NO}_{2}{ }^{-} \rightarrow \mathrm{NO} \rightarrow \mathrm{N}_{2} \mathrm{O} \rightarrow \mathrm{N}_{2}
$$

A segunda reação envolve a redução do nitrato a amônia via nitrito, em um processo chamado amonificação, que ocorre em conjunto com o processo de metanogênese (Metcalf \& Eddy 1991, Akunna et al. 1992, Drtil 1995, Bernet \& Moletta 1998). O doador de elétrons pode ser obtido pela adição de uma fonte de carbono externa ou pelo uso do carbono que já existe no efluente a ser tratado (Akunna et al. 1992).

O processo de desnitrificação é predominante quando ocorre aumento do valor do $\mathrm{pH}$ pela alcalinidade produzida durante a conversão do nitrato a gás nitrogênio. $\mathrm{O}$ pH ótimo situa-se entre 7 e 8 . A temperatura afeta a taxa de remoção de nitrato e a taxa de crescimento microbiano (Metcalf \& Eddy 1991; Akunna et al. 1994; Bernet \& Moletta 1998).

A diminuição na lixiviação do nitrato é importante do ponto de vista anbiental, uma vez que, altas concentrações de nitrato no lixiviado podem provocar contaminaçóes de águas subterrâneas. $\mathrm{O}$ teor de $\mathrm{NO}_{3}^{-}$permitido para águas efluentes é $100 \mathrm{mg} \mathrm{L}^{-1}$ e para água potável é de $10 \mathrm{mg} \mathrm{L}^{-1}$ (Amdur et al. 1991). Considerando que o nitrato é uma substância tóxica para animais mamíferos e peixes, seus níveis de concentração devem ser monitorados. Cameron et al. (1995) encontraram $42 \mathrm{mg} \mathrm{L}^{-1}$ de $\mathrm{N}_{-\mathrm{NO}_{3}}^{-}$na solução percolada de solo no qual foi aplicado $200 \mathrm{~kg} \mathrm{ha}^{-1}$ de $\mathrm{N}$ na forma de chorume de suíno. Carry et al. (1997) determinaram perda de 8 a $19 \%$ de $\mathrm{N}^{-\mathrm{NO}_{3}}$ - por lixiviação em solos que receberam $400 \mathrm{~kg} \mathrm{ha}^{-1} \mathrm{de}$ $\mathrm{N}$ proveniente de chorume de suíno.

Nos países de clima temperado, onde se desenvolvem atividades agrícolas com uso intensivo de insumos, um dos grandes problemas ambientais que tem ocorrido é a poluição dos mananciais 
de águas subterrâneas pelo $\mathrm{NO}_{3}^{-}$lixiviado, comprometendo por demais a sua potabilidade. A possibilidade do retardamento das perdas por lixiviação através da imobilização de nutrientes pelos micro-organismos do solo e pela absorção das plantas, principalmente no verão, segundo Smith (1982), pode permitir um equilíbrio harmônico. Smith (1982) ainda relata que $70 \%$ do N presente no solo está imobilizado pela microflora do solo, demonstrando então sua contribuição para evitar perdas por lixiviação, pela sua conservação natural.

Os resultados obtidos nos experimentos mostraram que há maior degradação do dejeto na presença de micro-organismos do gênero Bacillus, e os resultados da lixiviação apontaram para um processo de desnitrificação por amonificação associada com a metanogênese, uma vez que houve redução das concentrações de nitrito e nitrato no lixiviado e aumento da amônia, sem aumento na geração de $\mathrm{CO}_{2}$.

\section{CONCLUSÃO}

A inoculação de bactérias do gênero $\mathrm{Ba}$ cillus favoreceu a degradação do dejeto de suíno quando aplicado ao solo.

Não houve aumento na geração acumula$\mathrm{da}$ de $\mathrm{CO}_{2}$ durante a degradação em função da inoculação, no entanto, os resultados da lixiviação demonstram que houve redução das concentraçôes de nitrito e nitrato no lixiviado e aumento da amônia apontando para um processo de desnitrificação por amonificação, possivelmente associada com a metanogênese, uma vez que não houve geração de $\mathrm{CO}_{2}$.

A menor lixiviação de nitrato causada pela inoculação de micro-organismos pode contribuir para a diminuição de danos ambientais, como a contaminação de águas subterrâneas por este íon.

\section{REFERÊNCIAS}

Akunna, J. C., Bizeau, C., Moletta, R. Denitrification in anaerobic digesters: possibilities and influence of wastewater COD/N-NOx ratio. Environmental Technology, v.13, n.1, p. 825-836, 1992.

Alves, H. B., Mochida, G. A., Cruz, G. J. G., Duma, M., Gomes. C. S. Precipitação química e cloração para combate a maus odores em estações de tratamento de esgoto anaeróbias. Sanare - Revista Técnica da Sanepar, Curitiba, v.21, n.1, p.19-32, 2004.

Amdur, M.O., Doull, J., Klaassen, C.D. Toxicology - The basic science of poisons. Pergamon, New York, 1991.

Anthonisen, A. C., Loehr R. C., Prakasam, T. B. S., Srinath, E. G. Inhibition of nitrification by ammonia and nitrous acid. Journal WPCF (Water Pollution Control Federation), v. 48, n.5, p. 835-852, 1976.

APHA: Standard methods for the examination of water and wastewater. 20th ed. Baltimore, MD: United Book Press, 1998.

ASSOCIAÇÃO BRASILEIRA DE NORMAS TÉCNICAS - ABNT - NBR 14283. Resíduos em solo - Determinação da biodegradação pelo método respirométrico, 1999.

Belli Filho, P., Castilhos Jr, A. B., Costa, R. H. R., Soares, S. R., Perdomo, C. C. Tecnologias para o tratamento de dejetos de suínos. R. Bras. Engenharia Agrícola e Ambiental, Campina Grande, v.5, n.1, p.166-170, 2001.

Bento, F. M., Carmargo, F. A. O., Okeke, B. C., Frankenberger, W. T. Comparative bioremediation of soils contaminated with diesel oil by natural attenuation, biostimulation and bioaugmentation, Bioresource Technology, v. 96, n.9, p. 1049-1055, 2005.

Bernet, N., Moletta, R. Anaerobic digestion and nitrogen removal from wastewaters. In: IV Seminario latinoamericano sobre tratamiento anaerobio de aguas residuales. Mar del Plata, v. 1, n.1, p. 495-506, 1998.

Bertoncini, E. I., Mattiazzo, M. E. Lixiviação de metais pesados em solos tratados com lodo de esgoto. Revista Brasileira de Ciência do Solo, v.23, n.3, p.737-744, 1999.

Bitton, G. Wastewater Microbiology, Wiley Liss Pub., New York, 2005. 
Boopathy, R., "Factors limiting bioremediation technologies", Bioresource Technology, v. 74, n.1, p. 63-67, 2000.

Cameron, K. C., Rate, A. W., Carey, P. L., Smith, N. P. Fate of nitrogen in pig effluent applied to a shallow stony pasture soil. New Zealand Journal of Agricultural Research, v. 38, n.4, p.533-542, 1995.

Carry, P. L., Rate, A. W., Cameron, K. C. Fate of nitrogen in pig slurry applied to a New Zealand pasture soil. Australian Journal of Soil Research, v.35, n.4, p.941-959, 1997.

Drtil, M., Németh, P., Kucman, K., Bodík, I., Kasperek, V. Acidobasic balances in the course of heterotrophic denitrification. Water Research, v.29, n.5, p. 1353-1360, 1995.

Kunz, A., Higarashi, M. M., Oliveira, P. A. Tecnologias de manejo e tratamento de dejetos de suínos estudadas no Brasil. Cadernos de Ciência \& Tecnologia, Brasília, v. 22, n.3, p. 651-665, 2005.

Lubberding, H. J. Applied anaerobic digestion. In: International course on anaerobic treatment. Wageningen Agricultural University/IHE Delft. Wageningen, 1995.

Metcalf, L., Eddy, H. P. Wastewwater Engineering: Treatment, disposal and reuse. McGraw Hill, 4 ed., N. Y, 2003.
Metcalf, L., Eddy, H. P. Wastewater Engineering. Treatment, Disposal, Reuse. McGraw-Hill Int. Ed., 3 ed., Singapore, 1991.

Ollivier, B., Magot, M. Petroleum Microbiology. Washington D.C., USA, ASM Press, 2005.

Ratkowsky, D. A. Handbook of nonlinear regression models. New York: M. Dekker, 1990.

Regazzi, A. J. Teste para verificar a igualdade de parâmetros e a identidade de modelos de regressão não linear. Revista Ceres, v.50, n.1, p.9-26, 2003.

Smith, M. S. Nitrogen value from plowing a sod. Soil Science News and Views, 1982.

Souza, C. F., Lucas Junior, J., Ferreira, W. P. M. Biodigestão anaeróbia de dejetos de suínos sob efeito de três temperaturas e dois níveis de agitação do substrato - considerações sobre a partida. Engenharia Agrícola, Jaboticabal, v.25, n.2, p. 530-539, 2005.

Vidalli, M. "Bioremediation: An overview", Pure Applied Chemistry. v. 73, n.7, p. 1163-1172, 2001. 